\title{
Improving perinatal and neonatal mortality in Sri Lanka: is it cost effective?
}

\author{
D P S Gunasekera ${ }^{1}$, P C Gunasekera ${ }^{2}$ \\ Sri Lanka Journal of Child Health, 2000; 29: 23-6
}

(Key words: perinatal mortality, neonatal mortality, Sri Lanka)

Sri Lanka has remarkable health statistics for a developing country with a per capita income of US\$ 837. In 1946 life expectancy in Sri Lanka for males and females was 43.9 and 41.6 years respectively. Life expectancy in 1991 had increased to 69.5 and 74.2 years for males and females. The maternal mortality rate which was 165.2 per 10000 live births in 1945 has been reduced to 2.3 per 10000 live births in 1996. The infant mortality rate (IMR) has declined dramatically from 263 per 1000 live births in 1935 to 15.9 per 1000 live births in $1997^{1}$. These successes can be attributed to several factors, namely, the political commitment of successive governments to provide free health and education, adoption of a multisectoral approach to health, immunization against 6 childhood diseases and integration of maternal and child health together with family planning. Nevertheless, these statistics should be viewed with caution since national averages often conceal a considerable variation among different geographic parts of the country. Ten districts recorded IMRs higher than the national average of 15.9, while 7 districts recorded IMRs of over $20^{1}$.

Sri Lanka has ratified the Convention on the Rights of the Child which in Article 6 enshrines every child's inherent right to life. Furthermore, the Programme of Action of the International Conference on Population and Development held in 1994 identified the following goals to be reached by the year 2000 :

- Reduce infant mortality rate by one third of the 1990 level or to 50 per 1000 live births whichever is lower.

- $\quad$ Reduce maternal mortality by half of the 1990 levels.

These goals also coincide with those of the World Health Organization's (WHO) Mother Baby Package, which strives to attain the aims of the Safe

\footnotetext{
${ }^{1}$ Senior Lecturer in Paediatrics, University of Sri Jayawardenapura, ${ }^{2}$ National Professional Project Officer, INFPA.
}

Motherhood Initiative and the World Summit for Children. These goals were considered at the time to be both technically feasible and financially affordable.

While considerable concern is expressed about reducing infant mortality further, most of the decline has taken place among children over the age of one month, reflecting the emphasis on control of childhood communicable diseases. However, relatively less efforts have been directed to reduce deaths during the perinatal period. IMR has declined over the years, from 24.2 in 1985 to 16.5 in 1995 , while the NNMR has reduced only from 16.2 to 12.5 in a similar period ${ }^{1}$.

WHO estimates that $50 \%$ or more of infant deaths in all countries in the South East Asian Region occur during the neonatal period ${ }^{2}$. In Sri Lanka, the neonatal mortality rate (NNMR) was 12.5 per 1000 live births in 1995 which accounted for $75.9 \%$ of the infant deaths in that year ${ }^{1}$. These infant deaths were related to prematurity and low birth weight (LBW) $(30 \%)$, infections specific to the perinatal period $(15 \%)$, intrauterine and birth asphyxia (6\%) and other respiratory conditions of the fetus and newborn (1 $3 \%)^{3}$.

\section{Maternal factors}

Pregnancy, labour and the puerperium are treacherous times for mothers and babies. Some of the factors that lead to perinatal and neonatal death result from inadequate care of mothers and babies, while the mother's health and nutrition also plays an important role.

Factors that affect perinatal and neonatal mortality include poor maternal health, inadequate antenatal care and inappropriate management of antenatal and intrapartum complications. Poor hygiene during delivery and the first critical hours after birth and poor quality of newborn care add to the mortality figures. World Bank statistics indicate that globally $30-40 \%$ of all infant deaths can be averted by good 
obstetric care alone and another $25 \%$ with immediate newborn care. That is, over $50 \%$ of all infant deaths can be prevented by effective antenatal, intrapartum and postpartum care ${ }^{4}$. Maternal complications and maternal deaths also have a direct bearing on perinatal and neonatal mortality. If a mother dies after delivery this often leads to death of the live born infant as well ${ }^{5}$.

WHO studies reveal that more than two thirds of all new born deaths occur in term well developed babies. Ensuring their survival does not require expensive technology, but simple preventive measures, and prompt extra care ${ }^{8}$. Attending to the needs of the newborn - resuscitation when necessary, immediate breast feeding, warmth, cleanliness, hygienic conditions for delivery and cord care, prevention, early detection and management of major diseases will ensure health and survival of these infants. These are all cost effective ways of reducing morbidity and mortality. By promoting exclusive breast feeding the Baby Friendly Initiative helps in this regard by minimising the risk of nosocomial infection.

\section{Implications of the low birth weight baby}

The perinatal mortality of a low birth weight baby (LBW) is higher than that of a fetus or infant of normal weight. Maternal factors influencing LBW include heavy physical work after mid pregnancy, pregnancy induced hypertension and eclampsia, placental abruption, anaemia, malaria and other infections, short birth interval and teenage pregnancy. Although low birth weight does not directly cause death, these babies are more prone to birth asphyxia and trauma. They do not adapt to extrauterine life well, being very susceptible to hypothermia and infection. LBW infants who do not die may have serious long term neurological or developmental problems. Of particular note here is the Barker's Hypothesis which states that LBW babies have a higher incidence of adult morbidity such as ischaemic heart disease and Diabetes Mellitus ${ }^{5}$. It is of concern to know that of the births in government hospitals in Sri Lanka in 1998 (excluding Killinochchi and Mullativu districts) the LBW rate was 17.8 per 100 live births. In 14 districts the rate was higher than the national average ${ }^{1}$.

Low birth weight girls need social consideration. They may continue throughout life to weigh less than others of their age and and give birth to a LBW infant thus passing the problem onto the next generation.

\section{What needs to be done}

\section{Nutritional intervention}

Interventions to change the nutritional status of women are complex and usually linked to long term economic development. The percentage of the population in Sri Lanka with income below the poverty line during the period $1989-1995$ was $22 \%{ }^{7}$.

Provision of iron and folic acid as well as other nutritional supplements and nutrition education of mothers were important recommendations of the study on low birth weight and neonatal morbidity and mortality conducted by the Family Health Bureau in $1987^{8}$. The use of mebendazole has been shown to be safe in pregnancy and would contribute significantly to reducing iron deficiency anaemia ${ }^{9}$. The use of malarial prophylaxis in pregnancy also contributes to a reduction in perinatal and neonatal deaths ${ }^{10}$.

The Participatory Nutrition Improvement Programme (PNIP), being conducted in the country at present, should have an impact on the incidence of LBW in Sri Lanka in the long term ${ }^{11}$.

\section{Training of Health Care Personnel}

Of the total registered live births in Sri Lanka in 1996, the proportion of live births that occurred in government hospitals was $86.3 \%$. Deliveries in Teaching Hospitals accounted for $33 \%$ of these births. Hence, midwives, nurses and junior doctors should be properly trained in providing life saving interventions such as basic neonatal resuscitation and proper newborn care. Written protocols that clearly define steps for routine management and the management of complications are invaluable as a basis for training and supervision.

\section{Supervision of Health Care Personnel}

Improving the quality of care of mothers and babies during the first week of the post partum period is necessary. If all is well a healthy mother and baby are discharged home after the birth in 24 hours. While the family members' help is important to the mother in the postpartum period, the care and support of a professional is also needed for the well being of the mother and baby during this period. The most appropriate caregiver for this role of observation and support is the public health midwife. It is therefore distressing to note that the home visits carried out during the first 10 days after birth by public health midwives (based on estimated deliveries) has declined sharply from $69.2 \%$ in 1995 to $58.5 \%$ in 
1996. Furthermore, the number of infant deaths reported by them has also reduced from $44.6 \%$ in 1995 to $34.7 \%$ in $1996^{12}$. Early identification of neonatal problems and prompt and appropriate referral would help reduce the number of early neonatal deaths. What is required is proper supervision and motivation of staff.

In 1997, while $98 \%$ of pregnant women were provided with antenatal care by trained personnel, and $95 \%$ of deliveries were performed by them, only $83.7 \%$ of women were immunized against tetanus. This lapse may have contributed to the 12 preventable cases of neonatal tetanus that year ${ }^{1}$. Similarly, 7 cases of early and late syphilis reported in 1997, could have been averted by simple VDRL testing and prompt treatment of the mother ${ }^{1}$. The Professional Colleges should play an advocacy role in these situations.

\section{Resource Allocation}

While the resource allocation to the health sector by the government was $2.54 \%$ of Gross Domestic Product (GDP) in 1971 this has declined to $1.56 \%$ in 1996. However, the defense expenditure has risen from $1.5 \%$ to $5.7 \%$ of the GDP during the same period $^{13}$. Thus, although of vital importance, it is extremely difficult to envisage sophisticated neonatal units being established in all major hospitals in the near future. While it is essential to have such units to further help reduce the mortality of newborns, it would be much more economical (in the present context) to stress on further improvement of preventive measures.

\section{Role of Professional Colleges}

Institutions such as the Colleges of Paediatricians, Community Physicians and Obstetricans and Gynaecologists have an important advocacy role to play in promoting improvements to perinatal care. In this regard, formation of a Perinatal Society is timely.

In order to provide quality care, the College of Obstetricians and Gynaecologists have identified the minimum requirements necessary for an obstetric unit which includes staffing, equipment and drugs for a delivery room. The development of a partogram for national use by the College of Obstetricians and Gynaecologists is a step towards improving intraparturn care. The introduction of the partogram would prevent prolonged labour which is a cause of perinatal sepsis and intrapartum asphyxia. Birth asphyxia often cannot be anticipated. Hence, the necessary equipment and skills should be available at every birth. The Neonatal Advanced Life Support (NALS) training programme initiated by the College of Paediatricians is one such example which trains health care personnel in acquiring these skills. However, it is not only sufficient to initiate such programmes, it is imperative to continue these training programmes and have the necessary equipment available on a continuing basis, as part of Continuing Medical Education (CME). A scheme of CME accreditation points for such programmes would further encourage participation.

\section{Comprehensive Health Management Information System}

In order to address the problem of perinatal mortality and morbidity in a systematic manner accurate national statistics are a prerequisite. Preliminary measures are the registration of stillbirths throughout the country. Data in perinatal mortality is presently not available at a national level. Hence, such statistics should be fed into the national health management information system. Periodic national audits would help identify possible interventions to reduce perinatal morbidity and mortality in addition to those carried out in individual hospitals.

\section{Information, Education and Communications Strategy (IEC)}

An information, education and communication (IEC) strategy is required at national and regional levels. Health care workers, decision makers in government, community and family should be targeted. IEC should be synchronized with the health services. Both mass media and interpersonal communication are needed. An example of effective use of IEC would be in the promotion of periconceptional intake of increased folic acid in order to prevent neural tube defects.

It takes time to reduce perinatal mortality. Even in a resource poor country such as Sri Lanka simple cost effective measures would still help reduce the perinatal morbidity and mortality. An equitable distribution of the available resources throughout the country is a prerequisite, and improving the service quality is another important aspect. In order to achieve all these goals it is essential for healthcare managers and policy makers to receive accurate and current information.

As a former Director General of WHO noted 'most of the conditions that result in neonatal death and severe morbidity can be prevented or treated without 
resorting to sophisticated and expensive technology, 14 .

\section{References}

1. Annual Health Bulletin 1998. Ministry of Health, Sri Lanka.

2. Health Situation in the South East Asia Region 1994-1997. World Health Organization, Regional Off ice for South East Asia, New Delhi, 1999.

3. Child and Maternal Mortality in Sri Lanka 1992 1995. Registrar General's Department, Ministry of Public Administration, Home Affairs and Plantation Industries, 1998.

4. Tinker A. Safe motherhood as a social and economic investment. Technical consultation on Safe motherhood. 18-23 October 1997. Colombo, Sri Lanka.

5. Koenig M A, Fauveau V, Chowdhury A 1, Chakraborly J, Kahn M A. Maternal mortality in Matlab, Bangladesh: 1976-85. Studies in Family Planning 1988; 19: 69-80.

6. Barker D J R Fetal origins of coronary heart disease. British Medical Journal 1995; 311:1714.

7. Perinatal Mortality. A listing of available information. Maternal Health and Safe Motherhood Programme, World Health Organization, Geneva 1996.
8. Human development Report 1998. United Nations Development Programme, New York; Oxford University Press, 1998.

9. Study on Low Birth Weight and Neonatal Morbidity and Mortality. Family Health Bureau. Ministry of Health and Women's Affairs. Colombo 1992.

10. de Silva N R, Sirisena J L G J, Gunasekera D P $\mathrm{S}$, Ismail $\mathrm{M} M$, de Silva $\mathrm{S} J$. Effect of mebendazole therapy during pregnancy on birth outcome. Lancet 1 999; 353:1145-9.

11. Ebrahim G J. Malaria during pregnancy. .Journal of Tropical Pediatrics. 1996; 42:62-3.

12. Participatory Nutrition Improvement Project, Ministry of Plan Implementation, Ethnic Affairs \& National Integration, 1997.

13. Annual Report on Family Health, Sri Lanka, 1996. Evaluation Unit, Family Health Bureau, Colombo, 1998. p3.

14. Economic Progress of Independent Sri Lanka. Central Bank of Sri Lanka 1998 p 276.

15. Maternal and Child Health and Family Planning: Current Needs and Future Orientation. World Health Organization. Geneva 1996. Report by the Director General, World Health Organization. Geneva 1993. 
